\title{
The Effects of Ethanol-Dissolved Propolis on Strawberry Preservation
}

\author{
Linting Hao ${ }^{a}$, Ya Luo ${ }^{b}$, Shu Luo ${ }^{c}$, Qin Mo ${ }^{d}$, Yajie Ling ${ }^{e}$, Cong Ge ${ }^{f}$ and \\ Haoru Tang ${ }^{\mathrm{g},}{ }^{*}$ \\ College of Horticulture, Sichuan Agricultural University, Chengdu, Sichuan, China \\ a787604513@qq.com, b173698873@qq.com, ‘626567947@qq.com, d943156105@qq.com, \\ e2208312818@qq.com, f442477804@qq.com and 91048019614@qq.com
}

Keywords: Strawberry, Propolis, preservation.

\begin{abstract}
For the development of fresh-keeping technology, strawberries were coated with different propolis concentrations of $1.5 \%, 2.0 \%, 2.5 \%$ and $3.0 \%$. The effect and physiology on strawberries fresh-keeping was estimated by the decay index, weight loss rate, the soluble solid and titratable acid content. The result shows that propolis coating preservation treatment can significantly decrease the strawberries decay index and weight loss rate, and inhibit soluble solids and titratable acid content. It also delayed the aging process of postharvest strawberries notably, as well as prolonged strawberry fruits freshness. The preservation effect of strawberries coated with the propolis concentration of $2.5 \%$ and $3.0 \%$ are better, of which $3.0 \%$ is the best.
\end{abstract}

\section{Introduction}

Strawberry (Fragaria ananassa Duch.) is a perennial herb of the Rosaceae berries, which has a desirable taste and a high nutrition value. Strawberries are highly perishable due to their active metabolism, which lead to short senescence periods that produce great limitations on storage and transportation. Therefore, strawberry preservation has been put up an important position in recent years [1,2].

Physical and chemical preservation are two main methods for strawberry fresh-keeping currently. However, most physical methods such as air conditioned storage require relatively large mechanical equipment and complicated management. Though chemical methods based on chemical agents are low cost and easy to handle, they have certain negative effects on human health and environment. To ensure a good quality, and edible safety of strawberry, the development of natural preservatives with green, non-toxic and stable performance is increasingly prominent $[3,4]$.

Propolis is a resinoid containing flavonoids consisted of honey pollen and some basic aromatic oil [5]. Previous studies show that propolis contain some certain antibacterial effects of chemical composition. Moreover, ethanol solution of propolis can be a safe and non-toxic film former with strong antioxidant effect. Now the research of propolis has been applied to agricultural production, such as fresh jujubes, grapefruit and Wenzhou mandarin postharvest fresh-keeping [6-9].

In this study, we aim to investigate the utility of different concentrations of ethanol-dissolved propolis coating on strawberry to find a best fresh-keeping effect, thus providing a more safe and effective way to storage strawberry.

\section{Materials and Methods}

\subsection{Test Materials}

Strawberries (variety 'toyonoka') are collected from the Shuangliu country in April 2014, All fruits were selected based on the same ripening stage ( $>80 \%$ red surface color), uniform size, absence of any physical damage and fungal infection. Propolis are purchased from the apiary near Ya 'an.

\subsection{Experimental Method}

\subsubsection{The Preparation of Ethanol-Dissolved Propolis Coating}

The configuration of the reagent refers to Dongqi Guo ${ }^{[7]}$. 


\subsubsection{Test Processing}

The strawberry samples are grouped according to different concentration treatments and control. The indicators for measurement include decay index, weight loss rate, total soluble solids content and titratable acid. Determining decay index, weight loss rate and titratable acid content respectively refer to Chuyan Wang ${ }^{[10]}$, Mingli Kang ${ }^{[11]}$ and Qing'e Xiong ${ }^{[12]}$. Using the WYT-4 handheld saccharimeter measures the soluble solids content.

\section{Results and Discussion}

\subsection{Effects of Different Concentrations of Propolis on the Decay Index of Strawberry Fruit.}

Table.1 shows that the decay index of the strawberry fruit treated with propolis was reduced to a different degree compared to contrast, especially 3.0\% treatment. Thus, it can be indicated that propolis coating can effectively prolong the freshness of strawberry fruits with the best inhibiting utility of $3.0 \%$ ethanol-dissolved propolis.

Table.1 Effects of different concentrations of propolis on the decay index of strawberry fruit

\begin{tabular}{cccccc}
\hline \multirow{2}{*}{ Treatments } & \multicolumn{5}{c}{ Decay index } \\
\cline { 2 - 6 } & Day0 & Day1 & Day2 & Day3 & Day4 \\
\hline CK & 0a & $1.13 \pm 0.12 \mathrm{a}$ & $1.37 \pm 0.15 \mathrm{a}$ & $3.20 \pm 0.26 \mathrm{a}$ & $3.70 \pm 0.17 \mathrm{a}$ \\
1.5\%propolis & 0a & $1.00 \pm 0.00 \mathrm{abc}$ & $1.33 \pm 0.15 \mathrm{a}$ & $2.73 \pm 0.21 \mathrm{ab}$ & $3.53 \pm 0.40 \mathrm{a}$ \\
2.0\%propolis & 0a & $1.10 \pm 0.10 \mathrm{ab}$ & $1.23 \pm 0.15 \mathrm{ab}$ & $2.97 \pm 0.47 \mathrm{ab}$ & $3.30 \pm 0.26 \mathrm{ab}$ \\
2.5\%propolis & $0 \mathrm{a}$ & $0.97 \pm 0.06 \mathrm{bc}$ & $1.03 \pm 0.06 \mathrm{~b}$ & $3.10 \pm 0.10 \mathrm{ab}$ & $3.650 \pm 0.10 \mathrm{a}$ \\
3.0\%propolis & 0a & $0.93 \pm 0.06 \mathrm{c}$ & $1.00 \pm 0.10 \mathrm{~b}$ & $2.67 \pm 0.38 \mathrm{~b}$ & $2.73 \pm 0.50 \mathrm{~b}$ \\
\hline
\end{tabular}

Note: Different letters indicate significant difference $(\mathrm{P}<0.05)$, the same below.

3.2 Effects of Different Concentrations of Propolis on the Weight Loss Rate of Strawberry Fruit.

Table. 2 shows that the weight loss rate of strawberry fruits in the four concentration groups treated with propolis was lower than that in the control group. Among them, the strawberry fruit with 3.0\% propolis coating treatment had the least weight loss during the preservation process. Hence it is more effective in delaying strawberry fruit lose weight.

Table.2 Effects of different concentrations of propolis on the weight loss rate of strawberry fruit

\begin{tabular}{cccccc}
\hline \multirow{2}{*}{ Treatments } & \multicolumn{5}{c}{ Weight loss rate(\%) } \\
\cline { 2 - 6 } & Day0 & Day1 & Day2 & Day3 & Day4 \\
\hline CK & 0a & $2.87 \pm 1.28 \mathrm{a}$ & $6.39 \pm 0.44 \mathrm{a}$ & $13.16 \pm 1.81 \mathrm{a}$ & $18.02 \pm 2.23 \mathrm{a}$ \\
1.5\%propolis & 0a & $1.45 \pm 0.31 \mathrm{a}$ & $3.87 \pm 1.15 \mathrm{~b}$ & $10.15 \pm 2.45 \mathrm{ab}$ & $13.77 \pm 2.86 \mathrm{ab}$ \\
2.0\%propolis & 0a & $2.19 \pm 1.13 \mathrm{a}$ & $4.18 \pm 0.93 \mathrm{ab}$ & $11.03 \pm 1.86 \mathrm{ab}$ & $14.24 \pm 0.26 \mathrm{ab}$ \\
2.5\%propolis & 0a & $2.35 \pm 1.92 \mathrm{a}$ & $5.74 \pm 2.01 \mathrm{ab}$ & $9.97 \pm 4.14 \mathrm{ab}$ & $13.48 \pm 4.84 \mathrm{ab}$ \\
3.0\%propolis & 0a & $1.19 \pm 0.26 \mathrm{a}$ & $3.62 \pm 0.11 \mathrm{~b}$ & $7.72 \pm 0.51 \mathrm{~b}$ & $11.12 \pm 1.85 \mathrm{~b}$ \\
\hline
\end{tabular}

\subsection{Effects of Different Concentrations of Propolis on the Soluble Solids Content of Strawberry}

\section{Fruit.}

Table.3 shows that the content of soluble solids in each group was increased first and then decreased, reaching the highest in the second day. The content treated with propolis was always higher than that of control group. Among them, the soluble solids content of the $3.0 \%$ coating group was the highest, and it was significantly different from that of the control group, which illustrates 3.0\% propolis had the best effect on inhibiting reduction of soluble solids. 
Table.3 Effects of different concentrations of propolis on the soluble solids content of strawberry fruit

\begin{tabular}{cccccc}
\hline \multirow{2}{*}{ Treatments } & \multicolumn{5}{c}{ Soluble solids content (\%) } \\
\cline { 2 - 6 } & Day0 & Day1 & Day2 & Day3 & Day4 \\
\hline CK & $8.57 \pm 1.85 \mathrm{a}$ & $8.73 \pm 2.38 \mathrm{a}$ & $8.97 \pm 0.60 \mathrm{~b}$ & $8.68 \pm 0.75 \mathrm{~b}$ & $5.80 \pm 2.40 \mathrm{~b}$ \\
1.5\%propolis & $8.57 \pm 1.85 \mathrm{a}$ & $10.03 \pm 1.80 \mathrm{a}$ & $10.58 \pm 1.68 \mathrm{ab}$ & $8.73 \pm 2.38 \mathrm{ab}$ & $7.05 \pm 0.79 \mathrm{ab}$ \\
$2.0 \%$ propolis & $8.57 \pm 1.85 \mathrm{a}$ & $11.75 \pm 0.82 \mathrm{a}$ & $11.38 \pm 1.21 \mathrm{a}$ & $10.13 \pm 1.80 \mathrm{ab}$ & $6.73 \pm 0.53 \mathrm{ab}$ \\
$2.5 \%$ propolis & $8.57 \pm 1.85 \mathrm{a}$ & $9.73 \pm 1.97 \mathrm{ab}$ & $9.77 \pm 1.38 \mathrm{ab}$ & $9.73 \pm 1.97 \mathrm{a}$ & $7.32 \pm 1.17 \mathrm{ab}$ \\
$3.0 \%$ propolis & $8.57 \pm 1.85 \mathrm{a}$ & $10.13 \pm 1.80 \mathrm{a}$ & $11.67 \pm 0.43 \mathrm{a}$ & $11.75 \pm 0.82 \mathrm{a}$ & $8.87 \pm 1.80 \mathrm{a}$ \\
\hline
\end{tabular}

\subsection{Effects of Different Concentrations of Propolis on the Titratable Acid of Strawberry Fruit.}

Table. 4 shows that the titratable acid content reached a maximum on the first day for all groups, and then began to decrease. During the whole preservation period, the titratable acid content of the $1.5 \%$ coating group was close to the control group and had the worst effect. Nevertheless, the content of 3.0\% coating treatment group was always the highest, and it was significantly different from that of the control group. Therefore, it still had the best effect on delaying reduction of titratable acid.

Table.4 Effects of different concentrations of propolis on titratable acid content of strawberry fruit

\begin{tabular}{cccccc}
\hline \multirow{2}{*}{ Treatments } & \multicolumn{5}{c}{ Titratable acid(\%) } \\
\cline { 2 - 6 } & Day0 & Day1 & Day2 & Day3 & Day4 \\
\hline CK & $1.04 \pm 0.06 \mathrm{a}$ & $1.05 \pm 0.23 \mathrm{~b}$ & $0.61 \pm 0.09 \mathrm{~b}$ & $0.53 \pm 0.02 \mathrm{~b}$ & $0.45 \pm 0.06 \mathrm{c}$ \\
1.5\%propolis & $1.04 \pm 0.06 \mathrm{a}$ & $1.53 \pm 0.20 \mathrm{ab}$ & $0.76 \pm 0.07 \mathrm{ab}$ & $0.55 \pm 0.04 \mathrm{~b}$ & $0.51 \pm 0.06 \mathrm{bc}$ \\
$2.0 \%$ propolis & $1.04 \pm 0.06 \mathrm{a}$ & $1.14 \pm 0.06 \mathrm{~b}$ & $0.85 \pm 0.13 \mathrm{a}$ & $0.71 \pm 0.08 \mathrm{a}$ & $0.57 \pm 0.03 \mathrm{ab}$ \\
2.5\%propolis & $1.04 \pm 0.06 \mathrm{a}$ & $1.20 \pm 0.35 \mathrm{~b}$ & $0.91 \pm 0.14 \mathrm{a}$ & $0.67 \pm 0.04 \mathrm{a}$ & $0.56 \pm 0.05 \mathrm{ab}$ \\
3.0\%propolis & $1.04 \pm 0.06 \mathrm{a}$ & $1.82 \pm 0.31 \mathrm{a}$ & $0.91 \pm 0.10 \mathrm{a}$ & $0.72 \pm 0.04 \mathrm{a}$ & $0.62 \pm 0.07 \mathrm{a}$ \\
\hline
\end{tabular}

\section{Conclusion}

This experiment use ethanol-dissolved propolis coatings with different concentrations of propolis to identify the optimum concentration on the preservation of strawberry. The results shows that different propolis concentration will affect the quality of strawberry during storage. And the best treatment, with 3.0\% propolis coatings, can effectively restrain the decay and weight loss process of strawberry, and delay the reduction of soluble solids and titratable acid content during fresh-keeping. In conclusion, higher concentration of propolis coatings work well in the preservation of 'toyonoka' strawberry fruits, which provides some reference value and significant discussion for the application of coating agent on strawberry fresh-keeping.

\section{References}

[1]. Yinghu Zhao, Xiaoyan Yan, Li Gao. Effect of Clove Alcohol Extract to the Preservation of Strawberries[J]. Shanxi Agricultural Science, 2012,40(6):677-681

[2]. Lihua Zhang, Yuanhu Zhang, Hui Cao. Effects of pomegranate peel extract on keep-freshing of strawberry[J]. Transactions of the Chinese Society of Agricultural Engineering, 2010, 26(2): 361-364.

[3]. Yanfang Ren, Chang Liu, Junyu He. Research Advances in Application of Chinese Herb Extracts to Postharvest Preservation of Fruits and Vegetable[J]. Food Research and Development, 2012, 33(1): 182-185. 
[4]. Li Wang. Problem and solution of strawberry storage preservation[J]. Xiandai Horticulture, 2011, (19): 21.

[5]. Erfang Xie. Abstract of propolis[J]. The Chinese Journal of Burns Wounds and Surface Ulcers, 1999, 1: 55.

[6]. Xue Qi, Zhen Li, Guixian Luo. Study on the chemical constituents and pharmacological action of propolis[J]. Heilongjiang Medicine journal, 2001, 17(4): 60.

[7]. Dongqi Guo, Qunxia Wang, Xujie Hou. The effect of propolis coating on the storage and preservation of round brittle dates[J]. Food science and technology, 2012, 37(4): 26-29.

[8]. Õzdemir A E, Çandir E E, Kaplankiran M, et al. The effects of ethanol-dissolved propolis on the storage of grapefruit cv. Star Ruby [J]. Turkish Journal of Agriculture and Forestry, 2010, 34: 155-162.

[9]. Zide Zhang, Junlian Ma. The effect of propolis on the preservation and physiological effects of Wenzhou mandarin. [C]. Proceedings of the second youth academic annual conference of China association of science and technology, Beijing, 1995: 726-729.

[10]. Chuyan Wang, Qijun Ai, Muying Du. Study on Antimicrobial Poperties of Pyola calliantha Extracts and Application in Strawberry Preservation [J]. Food Science , 2008, 29(1): 325-328.

[11]. Mingli Kang, Dehua Mou, Yan Li. Experimental study on the fresh strawberries with chitosan coating [J]. Northern Horticulture, 2005(6): 66-67.

[12]. Qing'e Xiong. Experimental course on plant physiology[M]. Sichuan science and technology press, 2003: 68-69, 30-31, 55-56. 